\title{
Supernumerary teeth with eumorphism in the lower incisor region: A report of five cases and a review of the literature
}

\author{
Yohko Fukuta ${ }^{\S}$, Morio Totsuka $^{\S}$, Yasunori Takeda \\ and Hirotsugu Yamamoto
}

\begin{abstract}
Department of Oral Diagnosis ${ }^{\S}$ and Department of Oral Pathology ${ }^{\dagger}$, School of Dentistry, Iwate Medical University, Morioka 020-8505

Department of Pathology $y^{\ddagger}$ Nihon University School of Dentistry at Matsudo, Matsudo 271-0061
\end{abstract}

(Received 6 May and accepted 15 October 1999)

\begin{abstract}
Five cases of supernumerary teeth with eumorphism in the lower incisor region of the permanent dentition are reported. The patients were two males and three females. One (a 31-year-old woman) of them had bilateral supernumerary teeth. The review of the English language literature yielded only one such bilateral supernumerary teeth in the lower incisor region of the permanent dentition was reported. (J. Oral Sci. 41, 199 202, 1999)

Key words: supernumerary tooth; eumorphic tooth; so-called five incisors; lower incisor region; permanent dentition.
\end{abstract}

\section{Introduction}

Two forms of anomalous tooth number are recognized: supernumerary (hyperodontia) and congenital absence (hypodontia) (1). Generally, the incidence of supernumerary teeth is lower than that of congenitally absent teeth, and hyperodontia involves only a single tooth, in contrast to hypodontia (1). It has been suggested that tooth number in humans is gradually decreasing with the progress of evolution.

Supernumerary teeth are found most frequently in the incisor and molar regions of the maxilla (1-5). Another common site is the lower premolar region. On the other hand, supernumerary teeth in the lower incisor region in the permanent dentition are rare, and bilateral supernumerary teeth in the lower incisor region are extremely rare. Here we report five cases of supernumerary teeth in the lower incisor region, including one case of bilateral supernumerary teeth.

\section{Case Report}

The files of 28,590 outpatients seen between 1983 and 1997 at the Department of Oral Diagnosis of the Dental Hospital of Iwate Medical University were reviewed, and seven patients with supernumerary teeth in the lower incisor region of the

Correspondence to: Dr. Yohko Fukuta, Department of Oral Diagnosis, School of Dentistry, Iwate Medical University, 1-3-27 Chuo-dori, Morioka 020-8508, Japan permanent dentition were found (incidence, $0.024 \%$ of all cases). Of these seven cases, two have been reported previously $(6,7)$. The five newly added cases with eumorphic teeth were as follows:

Case 1 was a 24-year-old Japanese man with five incisors in the mandible (Fig. 1). The tooth, located in the mesial region of the left canine, was probably supernumerary, since

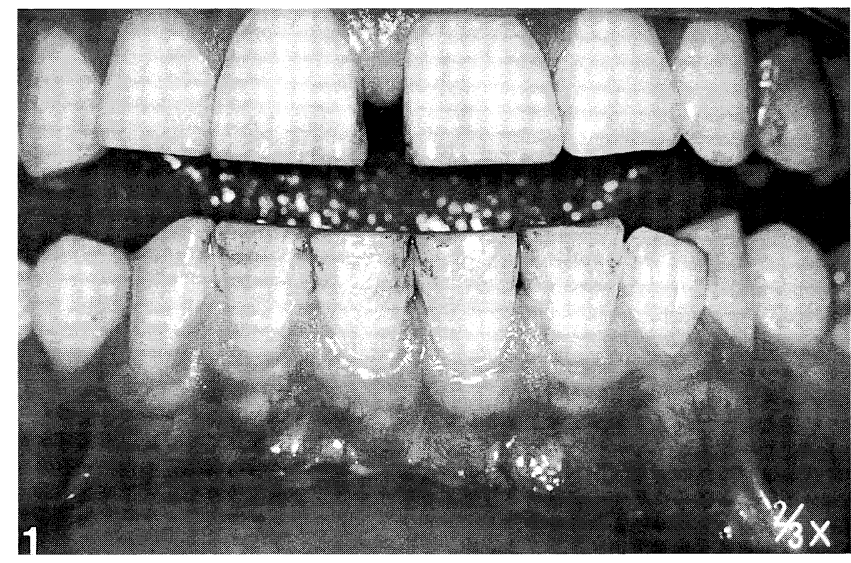

Fig. 1 Case 1: 24-year-old man with five incisors in the mandible.

it appeared smaller than the other incisors.

Case 2 was a 22-year-old Japanese man with five incisors in the mandible (Fig. 2). Differentiation between the normal teeth and the supernumerary one could not be made because

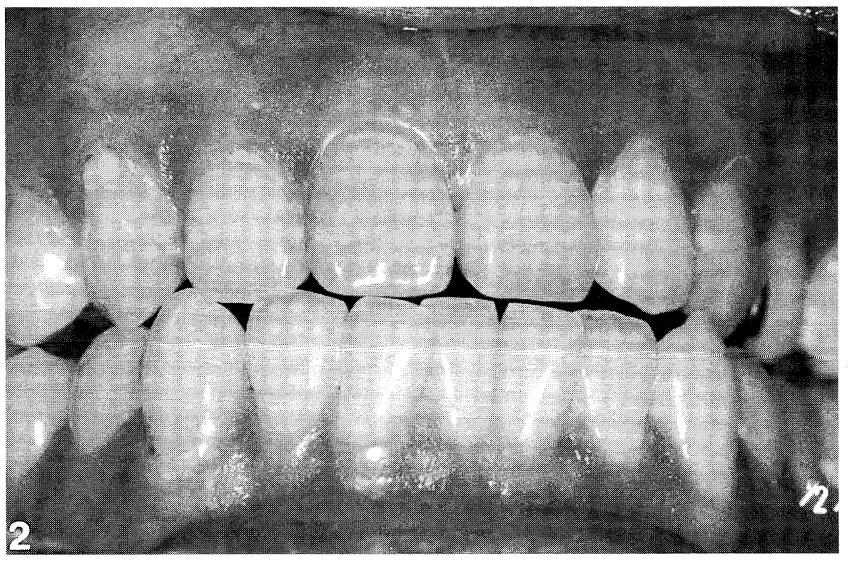

Fig. 2 Case 2: 22-year-old man with five incisors in the mandible. 
of their eumorphism.

Case 3 was a 17-year-old Japanese girl. Dental examination revealed anterior cross-bite and five incisors with crowding in the mandible (Figs. 3A, 3B). The tooth, located in the mesial region of the left canine, was smaller than the neighboring incisors, as was revealed by measuring the crowns of the lower incisors using a plaster model. Radiographic examination revealed that its root was slightly shorter than those
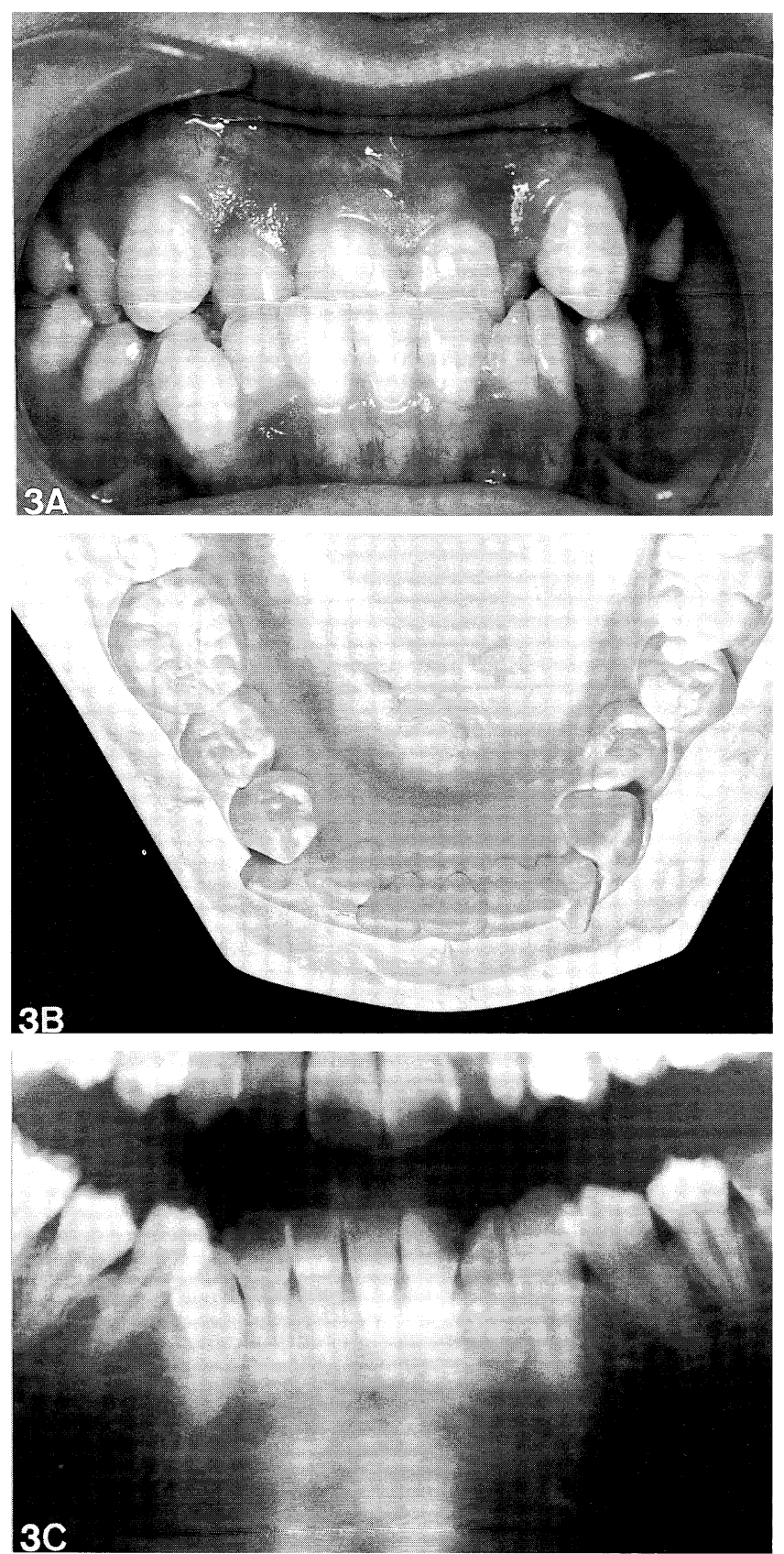

Fig. 3 Case 3: 17-year-old woman with five incisors in the mandible and anterior cross-bite. A, Labial view; B, Plaster model; C, Radiograph showing slightly short root of an incisor located in the mesial region of the left canine.
Case 4 was a 40-year-old Japanese woman with five incisors. The tooth, located in the mesial region of the left mandibular canine, was rotated (Figs. 4A, 4B). According to measurements of the crown sizes of these incisors using a plaster model, the central tooth was the smallest, but a radiograph revealed that the roots of all incisors were normal in both shape and length (Fig. 4C).
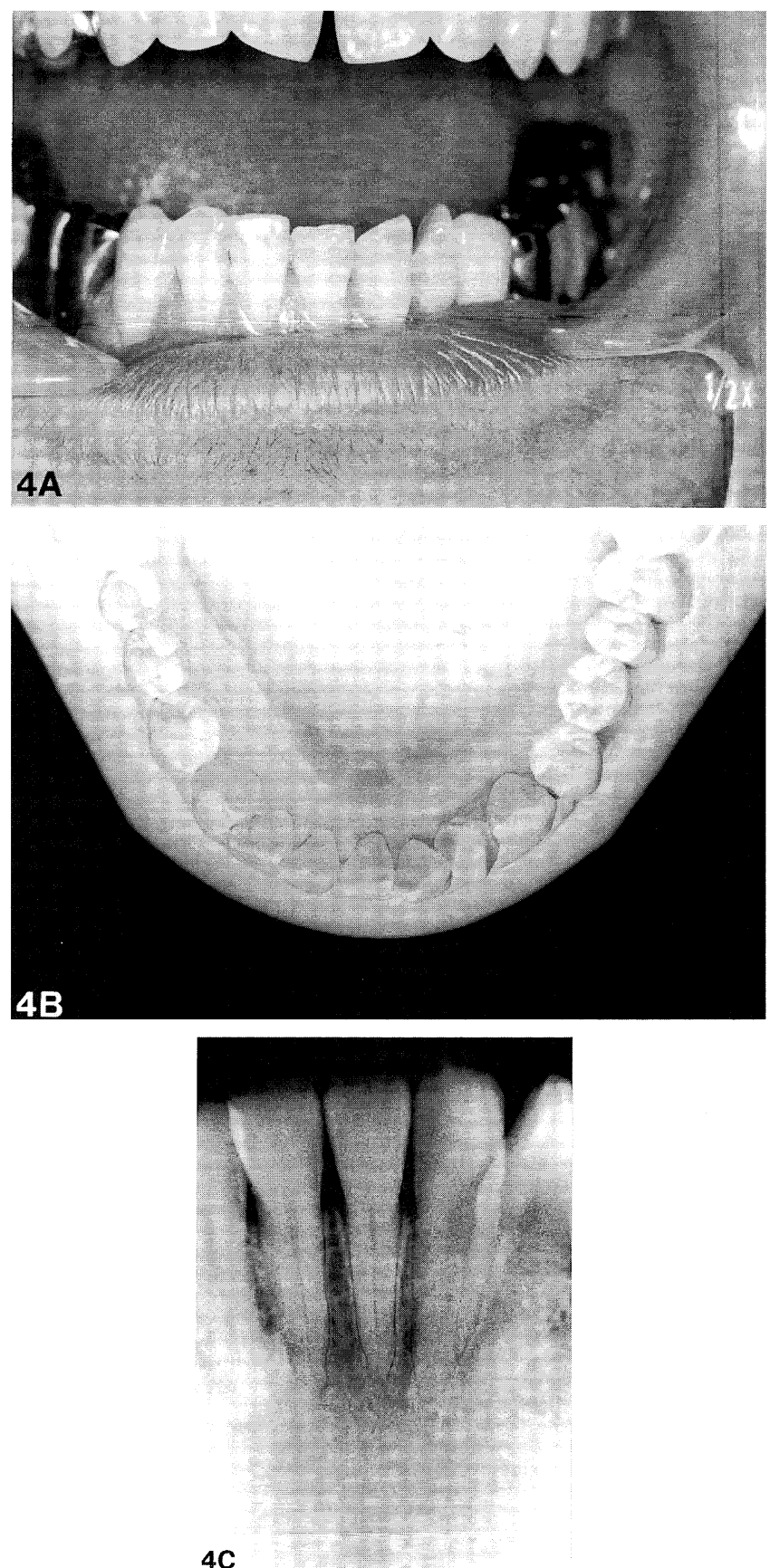

Fig. 4 Case 4: 40-year-old woman with five incisors in the mandible. A, Labial view; B, Plaster model; C, Intraoral radiograph showing the normal shape and length of the roots of the incisors.

of the other incisors (Fig. 3C). 
Case 5 was a 31 -year-old Japanese woman with six incisors in the mandible with crowding (Figs. 5A,5 B). The teeth located in the mesial region of the left canine were fused. It was thought that these fused teeth were geminated teeth, because of their mirror-image appearance with equal size, shape and development. The second tooth, located in the mesial region of the right canine, was the smallest according to measurements of the crown using a plaster model. A panoramic radiograph revealed that the fused teeth were combined together with the crown, and that all the lower incisors had roots of normal shape and length (Fig. 5C).
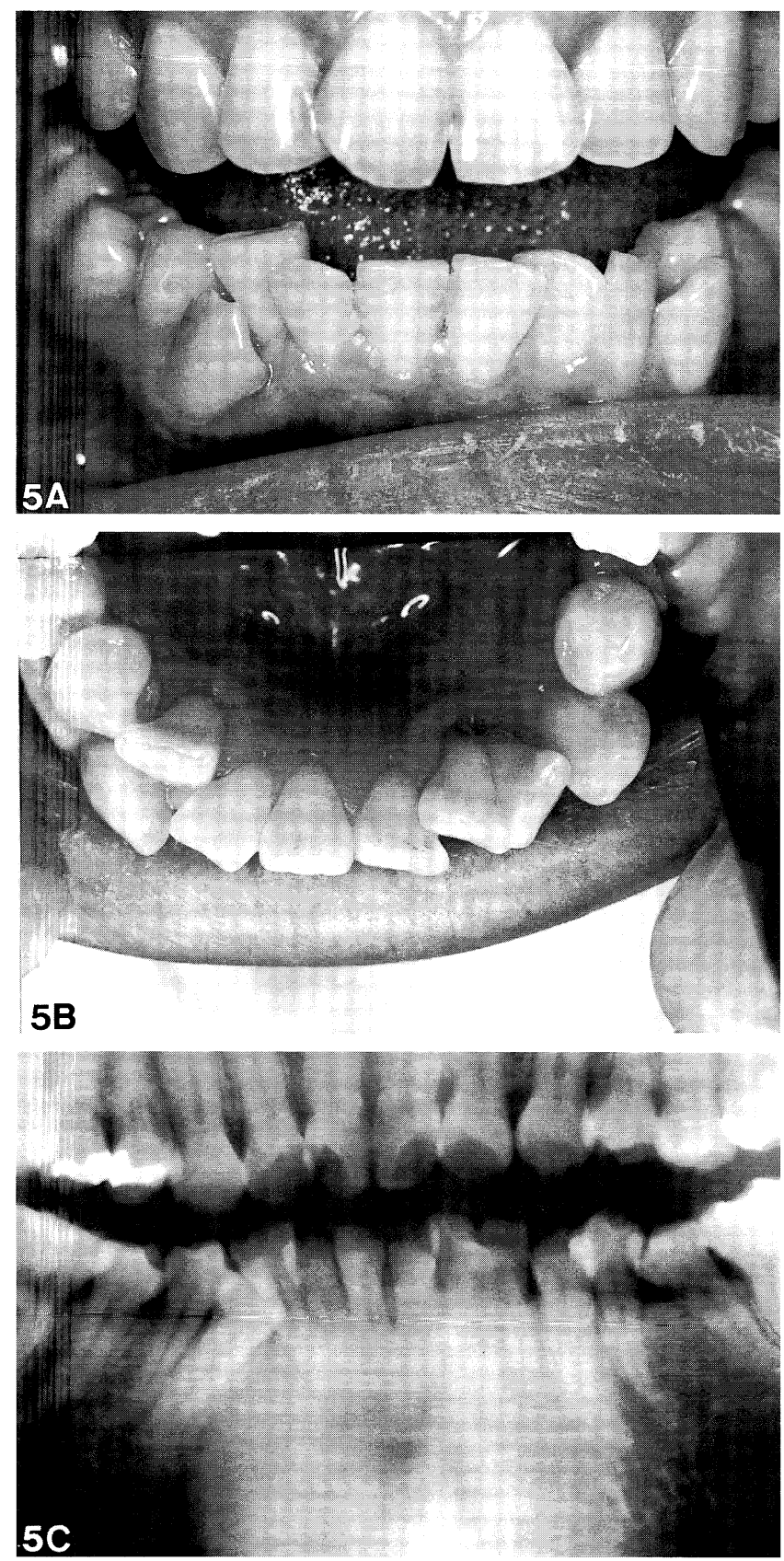

Fig. 5 Case 5: 31-year-old woman with bilateral supernumerary teeth in the lower incisor region showing gemination on the left side. A, Labial view; B, Plaster model; C, Radiograph showing normal shape and length of the roots of the incisors.

\section{Discussion}

The occurrence of supernumerary teeth in the permanent dentition is higher than in the deciduous dentition $(4,5)$, and its incidence ranges from $1 \%$ to $3 \%$ (8-11). Supernumerary teeth in the lower incisor region are very rare. Stafne (2) found supernumerary teeth in the lower incisor region in only 10 $(0.02 \%)$ of 48,550 patients, and others have reported figures of $0.12 \%(8), 0.13 \%(9)$, and $0.03 \%$ (11). Most of the supernumerary teeth reported in the incisor region of the permanent dentition have been found unilaterally and show eumorphism, and cases involving such supernumerary teeth have been termed five incisors (12) or supplementary teeth $(1,3)$. Some patients with so-called five incisors show a normal dental arch, but others have esthetic problems. Bilateral supernumerary teeth in the lower incisors are extremely rare; including the present case, only four such cases have been reported (6). In addition, Robertson (13) has reported a girl showing bilateral, unerupted supernumerary teeth in both the deciduous and permanent dentitions. Generally, supernumerary teeth are found predominantly in men $(1,2,3,8,10,11)$, but bilateral supernumerary teeth in the lower incisor region can occur in women.

The present case with bilateral supernumerary teeth in the incisor region showed gemination in one of them. Gemination of lower incisors in the permanent dentition is rare. In the incidence of gemination Sumiya (14) reported as $0.1 \%$ and Ruprecht (15) reported as $0.3 \%$, but no lower permanent incisors were included. Buenviaje (16) reported an incidence of $0.08 \%$, but the region of gemination was not described. Gemination results from either incomplete division of a single dental germ (schizodontism) or fusion of two adjacent, regular or accessory germs (synodontism) (3). In the present case, we suspected that the geminated teeth had resulted from incomplete division of a single tooth germ, because the teeth had a mirrorimage appearance, with equal size, shape and development. It has been suggested that gemination may be hereditary (4), although in the present case we were unable to obtain any family data.

It is suspected that supernumerary teeth occur through cleavage or hyperproduction of the tooth germ. Supernumerary teeth may have a tendency to occur in areas where the distance between tooth germs is wide, and the rarity of supernumerary teeth in the lower incisor region may be due to the narrow distance between the tooth germs. Cleavage or hyperproduction of the tooth germ can occur through developmental disturbance of the jaws associated with cleft lip and palate (1). Furthermore, genetic or systemic factors have also been implicated in the development of supernumerary teeth, e.g. cleidocranial dysostosis $(1,3,4)$, Gardner's syndrome (4), or Ehlers-Danlos syndrome (17). Familial or hereditary causes have also been described $(4,17,18)$. However, no definite cause could be deduced for the present series of supernumerary teeth. 


\section{References}

1. Pindborg, J.J. (1970) Abnormalities of tooth morphology. In Pathology of the dental hard tissues, Munksgaard, Copenhagen, 26-33

2. Stafne, E.C. (1932) Supernumerary teeth. Dent. Cosmos 74, 653-659

3. Schulze, C. (1970) Developmental anomalies of the teeth and jaws. In Thoma's oral pathology. Vol. 1, 6th ed., Gorlin, R.J. and Goldman, H.M. eds., C.V. Mosby, St. Louis, 112- 123

4. Shafer, W.G., Hine, M.K. and Levy, B.M. (1983) Disturbances of development and growth. In A textbook of oral pathology. 4th ed., W. B. Saunders, Philadelphia, $38-51$

5. Soames, J. V. and Southam, J. C. (1998) Disorder of development of teeth. In Oral pathology, 3rd ed., Oxford Unversity Press, Oxford, 4-5

6. Totsuka, M., Ogawa, K., Fukuta, Y. and Ono, M. (1984) A case of supernumerary tooth in lower anterior region. Iwate Ika Daigaku Shigaku Zasshi 9, 118-127 (in Japanese)

7. Fukuta, Y., Totsuka, M. and Takeda, Y. (1999) Two atypical supernumerary teeth in the lower anterior region: a case report. Nihon Koku Shindan Gakkai Zasshi 12 (in Japanese, in press)

8. Bergström, K. (1977) An orthopantomographic study of hypodontia, supernumeraries and other anomalies in school children between the age of 8-9 years. An epidemiological study. Swed. Dent. J. 1, 145-157

9. Ruprecht, A., Batniji, S. and El-Neweihi, E. (1984) Incidence of supernumerary teeth. Ann. Dent. 43, 1821
10. Davis, P. J. (1987) Hypodontia and hyperdontia of permanent teeth in Hong Kong schoolchildren. Community Dent. Oral Epidemiol. 15, 218-220

11. Ogita, S., Ogita, M., Yamamoto, T., Yanase, H., Kondo, Y. and Yokoi, K. (1995) The appearance of supernumerary teeth and congenitally missing in Japanese pediatric patients. Aichi-Gakuin Daigaku Shigakkai Shi 33, 19-27

12. Tioda, M., Ando, M. and Swe Win, K. K. (1994) Mandibular fiveincisors. A rare supernumerary tooth in the mandibular incisor region. Hosp. Dent. Oral Maxillofac. Surg. (Tokyo) 6, 10-11

13. Robertson, N. R.E. (1962) Supplemental incisors in the deciduous and permanent dentitions. Dent. Practit. $13,150-151$

14. Sumiya, Y. (1959) Statistic study on dental anomalies in the Japanese. Zinruigaku Zasshi 67, 215-233 (in Japanese)

15. Ruprecht, A., Batniji, S. and El-Neweihi, E. (1985) Double teeth: the incidence of gemination and fusion. J. Pedod. 9, 332-337

16. Buenviaje, T.M. and Rapp, R. (1984) Dental anomalies in children: a clinical and radiographic survey. ASDC J. Dent. Child. 51, 42-46

17. Melamed, Y., Barkai, G. and Frydman, M. (1994) Multiple supernumerary teeth (MSNT) and EhlersDanlos syndrome (EDS): a case report. J. Oral Pathol. Med. 23, 88-91

18. Yamasaki, Y. (1961) High incidence of supernumerary incisors in one family, case report. Kokubyo Gakkai Zasshi 28, 105-109 (in Japanese) 